\title{
Comparison in Pattern of Quality of Life in Different Regions
}

Behzad Einollahi ${ }^{1}$, Shima Shahyad ${ }^{2 *}$, and Aidin Lotfiazar ${ }^{1}$

${ }^{1}$ Nephrology and Urology Research Center, Baqiyatallah University of Medical Sciences, Tehran, IR Iran

${ }^{2}$ Neuroscience Research Center, Baqyiatallah University of Medical Sciences, Tehran, Iran

*Corresponding author: Shima Shahyad, Neuroscience Research Center, Baqyiatallah University of Medical Sciences, Tehran, Iran, Tel: +98 2182483347 ; E-mail: shima.shahyad@gmail.com

Received date: September 07, 2016; Accepted date: September 30, 2016; Published date: October 07, 2016

Copyright: ( 2016 Einollahi B, et al. This is an open-access article distributed under the terms of the Creative Commons Attribution License; which permits unrestricted use; distribution; and reproduction in any medium; provided the original author and source are credited.

\section{Letter to Editor}

We recently read with interest the article by Abdelghany et al. entitled "Assessment of Health-Related Quality of Life in Patients Receiving Regular Hemodialysis" published in your esteemed journal [1]. They showed that Physical Health Composite and mental component summary scores in Egyptian hemodialysis (HD) patients were $35.57 \pm 7.34$ and $36.76 \pm 10.22$ respectively.

We have also investigated health related quality of life among Iranian HD patients [2]. Physical and Mental component summary scores in Iranian HD patients were 40.79 and 47.79 respectively [2]. Moreover, these parameters were different in American HD patients (34.4-37.7 and 41.73-41.7 respectively) [3] and Netherlands HD patients (38.8 and 43.7 respectively) [4]. One of the reasons for these differences could be due to cultural and health care system varieties between different countries. For example, in some Studies, HD patients received $3 \mathrm{HD}$ sessions per week, but in some other studies, HD patients received 2 or 3 HD sessions per week. The different ethnic groups may be another reason. For example, the prevalence of endstage renal disease (ESRD) and some risk factors of chronic kidney disease (CKD) such as hypertension and diabetes are widely different among various ethnic groups [2]. Age of participants, sample size and level of education which are different among countries are other important confounding factors. For instance, Iranian patients were younger in comparison to participants in other studies.

Finally, various studies had different reports about PCS and MCS, but the key when drawing conclusions from different studies is to make sure consider cultural diversity, research methodology, sample size, socio-demographic factors, ethnic groups and health care system.

\section{References}

1. Abdelghany MA, Elgohary EE, Nienaa YA (2016) Assessment of HealthRelated Quality of Life in Patients Receiving Regular Hemodialysis. J Nephrol Ther 6: 246.

2. Rostami Z, Einollahi B, Lessan-Pezeshki M, Abadi ASN, Kebar SM, et al. (2013) Health-related quality of life in hemodialysis patients: an Iranian multi-center study. Nephro-urology monthly 5: 901-912.

3. Unruh ML, Newman AB, Larive B, Dew MA, Miskulin DC, et al. (2008) The influence of age on changes in health-related quality of life over three years in a cohort undergoing hemodialysis. J Am Geriatr Soc 56: 1608-1617.

4. Thong MS, van Dijk S, Noordzij M, Boeschoten EW, Krediet RT, et al. (2009) Symptom clusters in incident dialysis patients: associations with clinical variables and quality of life. Nephrol Dial Transplant 24: 225-230. 